\title{
Leveraging on E-Learning Platform for Teaching Mathematics in High Schools
}

\author{
Abiola O.B. \\ Dept. of Computer Science \\ Afe-Babalola University \\ Ado-Ekiti, Nigeria
}

\author{
Adeyemo O.A. \\ Dept. of Computer Science \\ Afe-Babalola University \\ Ado-Ekiti, Nigeria
}

\author{
Olatunji K.A. \\ Dept. of Computer Science \\ Afe-Babalola University \\ Ado-Ekiti, Nigeria
}

\begin{abstract}
From previous research works, it has been observed that motivating students to learn mathematics is difficult especially when presented in the traditional way or traditional teaching format. This paper presents an electronic way to combat these challenges among students and also to enhance the teaching of the subject in high schools. This tool has been designed uniquely to provide a user friendly platform that can be accessed by both students and teachers and as such allow them to appreciate the beauty of mathematics as one of the compulsory subject in high schools. Also students can learn at their own pace and convenience. The effectiveness of the system was evaluated both formally and informally. Positive student and peer feedback indicates that the design and the implementation of the system which was carried out using PHP as front-end and MySQL as the backend have been successful and that the system will have a positive impact on students in the learning of mathematics.
\end{abstract}

\section{General Terms}

E-Learning, Mathematics

\section{Keywords}

Mathematics, E-learning, High Schools, Students, Teachers.

\section{INTRODUCTION}

The fact that mathematics is the queen of sciences as a result of its applications in physical sciences cannot be overemphasized. Mathematics is used throughout the world as an essential tool in many fields, including natural science, engineering, medicine, finance and the social sciences. Mathematics expresses itself everywhere in almost every facet of life: in nature, all around us and in the technologies in our hands. It is the language of engineering describing the understanding of all that is observed. The mathematics everyday and everywhere explores the many wonders and uses of mathematics in everyday lives. It has been around since the beginning of time and it mostly probably began with counting, also applied in nature, shapes, curves and patterns, games and puzzles, time and heavens to mention but few.

According to [1] Mathematics occupies a central position in the school curriculum. It is a core subject from the primary through the junior secondary to the senior secondary school levels of the educational system. This important position occupied by the subject in the school curricula is borne out of its role in scientific and technological development. The question is, how can the challenges of inadequate and substandard learning materials and general attitudes among others be overcome with the teaching of this inevitable and important subject.
There is need to increase the level of awareness of students and even the society as a whole on the relevance and importance of mathematics so as to increase students' achievement in the subject especially in high schools since its societal values and views about its importance among the school subjects have not been fully explored. The point is some outstanding challenges about this subject remain unresolved especially among pupils in high schools where the basis of this inevitable subject began. There is need to make the teaching and learning of mathematics more user friendly by providing a more meaningful and electronically enhanced access to the subject to assist teachers in the proper dissemination of the subject as well as students in the learning process so as to protect the interest of the subject in today's flow of globalization, provide added value and better relationships between teachers and students.

The only way to achieve the above mentioned points is to provide an electronic platform (an e-learning platform) that can improve the learning and teaching of the subject in high schools where students are introduced to the foundational aspect of the subject so as to prepare them for future career. In a nutshell, e-learning platform for teaching mathematics is an online teaching system for students in high schools to learn, get additional knowledge on the already or to be thought subjects, give room for discussions, tutorials, questions and answers. This means that, from the comfort zones of each student learning is made possible through a web-based elearning system and also, teachers can make materials, assignments etc available for students without face to face contacts with them.

\section{DEFINITION OF E-LEARNING}

Previous studies have shown that motivating students to learn through an electronic means has greatly improved their performances. The concept of E-learning is very broad. It was coined in late $90 \mathrm{~s}$ as the technological enhanced learning mechanism through Internet. Now it captures a broad range of electronic media like Internet, Intranets, Extranets, satellite broadcast, audio or video tape, interactive TV and CD-ROM to make learning procedure more flexible and user friendly. [10]

But what exactly is e-learning? Different researchers have given various definitions to this concept according to their subject domain under discussions.

E-learning is about information, communication, education and learning. It is a platform with flexible learning using Information Technology and Communication (ITC) resources, tools and applications, and focusing on interactions among teachers, learners and online environment. Because of the flexible nature of e-learning and since it provides the right information in right time and in right place, students are now 
more familiar and feel more comfort in this new education system as affirmed by [10]

E-learning is the intentional use of networked information and communications technology in teaching and learning. A number of other terms are also used to describe this mode of teaching and learning, they include: online learning, virtual learning, distributed learning, network and web-based learning. The term e-learning comprises a lot more than online learning, virtual learning, distributed learning, networked or web-based learning. As the letter "e" in e-learning stands for the word "electronic", e-learning would incorporate all educational activities that are carried out by individuals or groups working online or offline, and synchronously or asynchronous. [11]

The teaching and learning of computer studies in high school in developing countries of the world will achieve a better result if the instrumentality if electronic learning is deployed. As the penetration of internet increases, accessibility to quality and relevant materials through e-learning platform will provide an alternative method to compliment the traditional way of teaching and learning as affirmed in [4].

E-learning is the use of electronic applications and processes technologies to transfer skills and knowledge in tertiary education. It has been introduced at many universities and colleges as one strategy with which to transform teaching and learning. Many institutions of higher education have turned to e-learning for authentic learning and to enhance learning performance. From reviews less than 5 percent of students expressed a dislike of e-learning tools, while 95 percent accepted them. [6].

E-Learning is being presented in the marketplace as the next evolution of the training and education industry and the next phase in the digital revolution as affirmed by [5].

It is essentially the computer and network enabled transfer of skills and knowledge. It refers to using electronic applications and processes to learn. E-learning applications and processes include web-based learning, computer-based learning, virtual classrooms and digital collaboration. Content is delivered via the Internet, Intranet or Extranet, audio or video tape, Satellite TV and CD-ROM. [8].

E-learning system has a lot of benefits which are cost efficiency, accessibility and flexibility among others. This type of system allows learners to access correct and up to date information in their subject areas and they are able to access materials and benefit from learning when required. In essence, it is a computer-based educational tool system that enables learners to learn anywhere and anytime. Whether you're a high-school teacher looking to engage your students in a more interactive way, or a corporate trainer hired by a large company to design training, curricula, e-learning packs a punch when it comes to benefits that make the creation and delivery processes easier and hassle-free. It is also cost effective as students can always get updated versions of textbooks online. It is especially useful for students who are introverts and find it very difficult to communicate openly inside the classroom.

\section{METHODOLOGY}

This section discusses the methods of study adopted in the design of the e-learning platform for teaching mathematics in high schools. The core objective of this work is to design the system and Implement it and also evaluate the system to determine its usefulness. The methodologies include the operational flow diagram of the system as well as the architectural design used in the design and analysis stage of the system for effective Implementations.

\subsection{Sources of Data}

The sources of data for the purpose of this design include primary data and secondary data respectively. Primary data is that which was used empirically. That is analysis of this data leads directly to particular themes or conclusions. For the purpose of this research a survey was conducted to access both students and teachers in some high schools to know their various views on the proposed system and this employed the quantitative approach and extensive interviews with teachers and students of some selected high schools. Findings used were based on preference for an e-learning platform because it would be more efficient and easy to manage while secondary data is that which was used to support the findings of the primary data. The secondary data was obtained from schools, Journals, Library sources and Internet downloads.

\subsection{Operational Flow Diagram}

The operational flow diagram of the system is showed in figure 1 below: From the diagram, there are two categories of users: teachers and students. An administrator creates password for authentication for both parties. Once a student has been registered, he or she logs in to the system and enters the class to download files, materials, tutorials and assignments. Another important feature of this architecture is that, a student can also enters the chat room and chat with the teacher on the subject by entering detail information, questions and messages. This off course will be of immense benefit for some students who are introverts and as such find it very difficult to communicate and ask questions in the classroom and it will also provide added value and better relationship between teachers and students. From the teacher's homepage, a teacher can work on class, subject and students. $\mathrm{He}$ or she is allowed to perform the following: add student to the lists of his or her already existed students, view information of students, delete students from lists, enter subject details, delete subject, manage class and as well upload files, assignment and materials for students. The system has been design to provide a teacher-to-student interactive environment and as such enhance students' understanding of the subject. It has been designed with simplicity in mind with a user friendly graphical user interface. This simplicity allows students and teachers to use the platform without any training or special set-up and it can be accessed anytime. This system features both knowledge building and self assessment capabilities and teachers can also monitor each student activities and students can keep learning irrespective of their locations as it provides students with 24hours availability of resources.

\section{SYSTEM IMPLEMENTATION}

Implementation of the user friendly e-learning system was carried out for effective usage and a global platform for students and teachers to appreciate the beauty of the mathematics was created with hardware and software requirements respectively. The main use of the hardware requirement is to make sure the application functions well. The hardware requirements are: monitor, keyboard, a minimum of $2 \mathrm{~GB}$ RAM, screen of at least $800 \times 600$, and 10GB HDD space. While the software requirements are: web browser, PHP, MySQL and Apache. PHP was used as the front end and MySQL as the backend. Also, there is need for WAMP server or Apache. The software was tested on windows 7 and 8 as it has not been tested on other operating systems. 


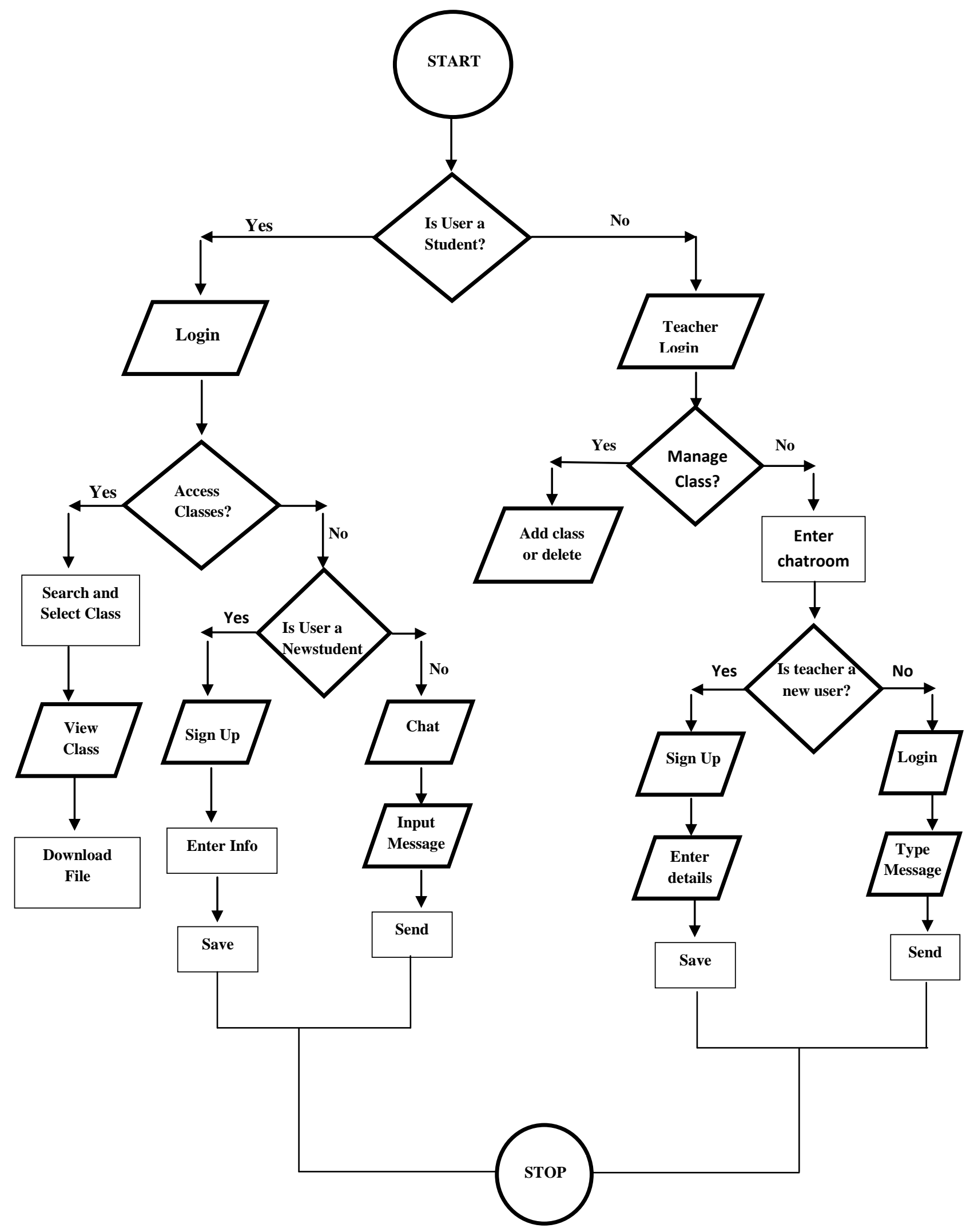

Figure 1. Operational Flow Diagram of the System 


\subsection{User Interface or Homepage Session}

This is the fundamental part that serves as entrance for both teachers and students. It is an Interactive page that allows users to navigate through the different pages that make up the web. The system is designed to be user friendly, affording a novice the opportunity to operate the system without many difficulties. Users only need to read instructions and adhere strictly to it; following one step after the other and on clicking the links will keep the user moving from page to page. Also, the links used in the system have self descriptive names such that a user can have at a glance, the entire structure of the system and decide on which page to visit.

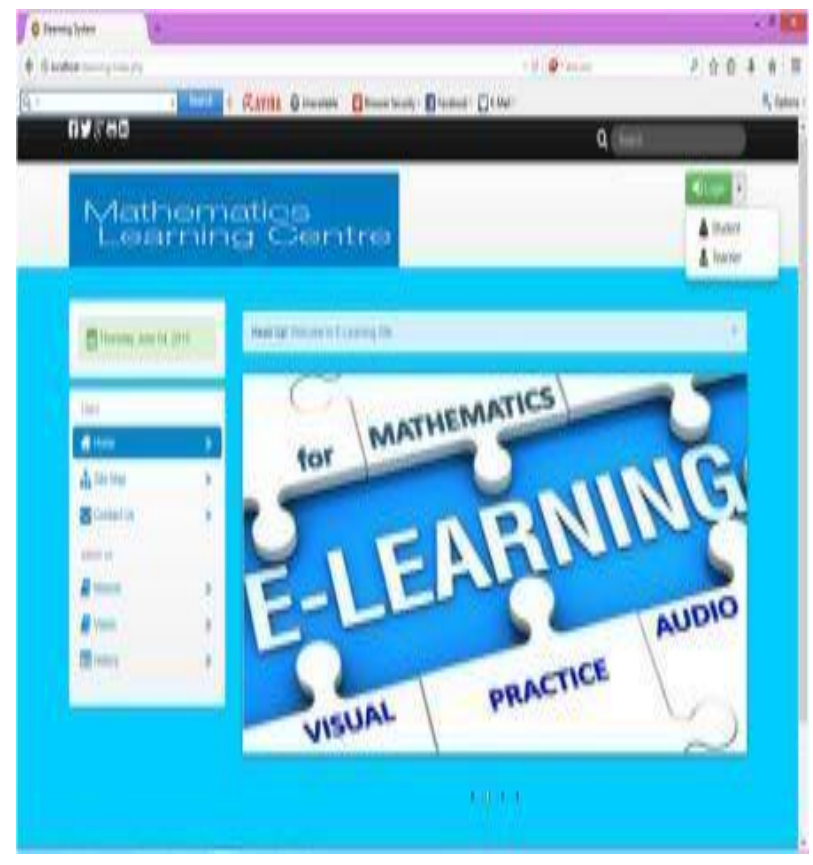

Figure 2. Teacher's Login Interface

\subsection{Teacher's Homepage Session}

Once a teacher has been given the login password for authentication by the admin, then the teacher can proceed to login in and carry out some activities on the home page. When a teacher enters the homepage the teacher can work on the class, the subject and the students. On the class interface, a teacher can enter class details and can also delete class. Then the teacher move on to upload files which can include tutorials, tests, assignment and other useful course materials for mathematics. The advantage of uploading course materials is that students who cannot afford the hard copies of such materials can easily get them online. Also, teachers can view students 'information and performances. The system is also designed in an interactive form to allow for teacher-to-student communication through chat room. This especially will assist students who are introverts to freely express themselves with the teacher in their private corners.

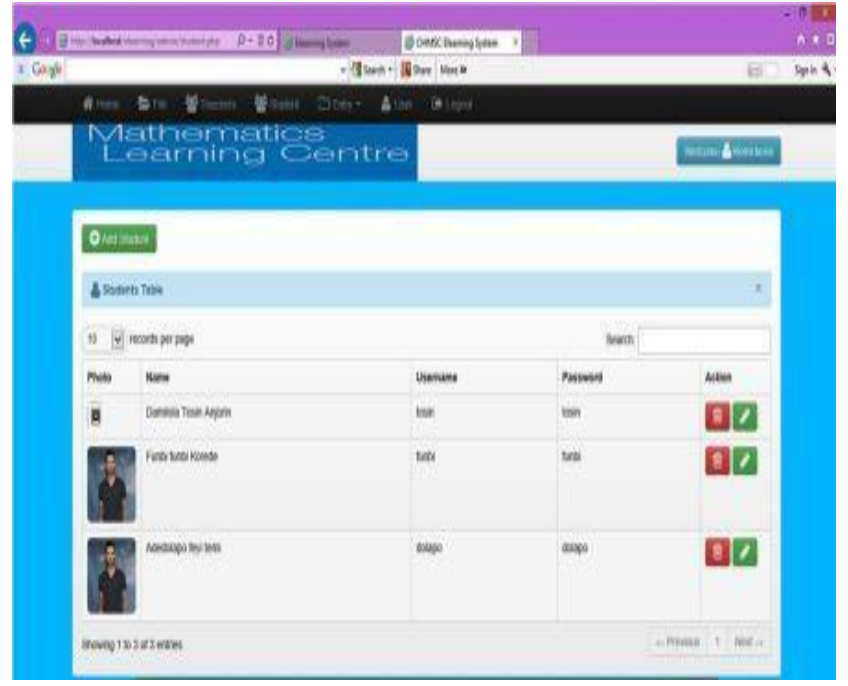

Figure 3. Lists of students added to the class

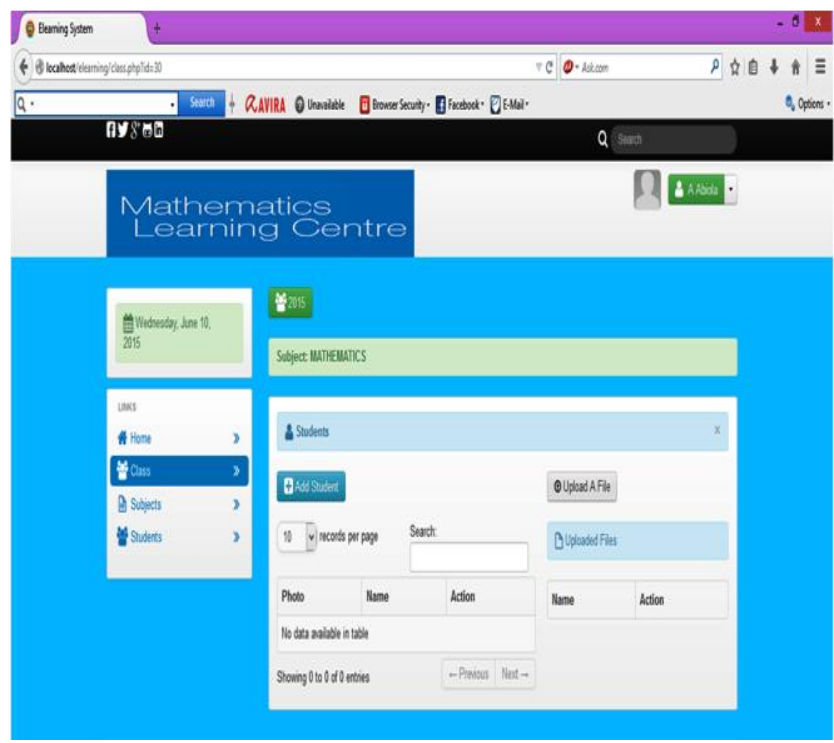

Figure 4. Upload of File Interface

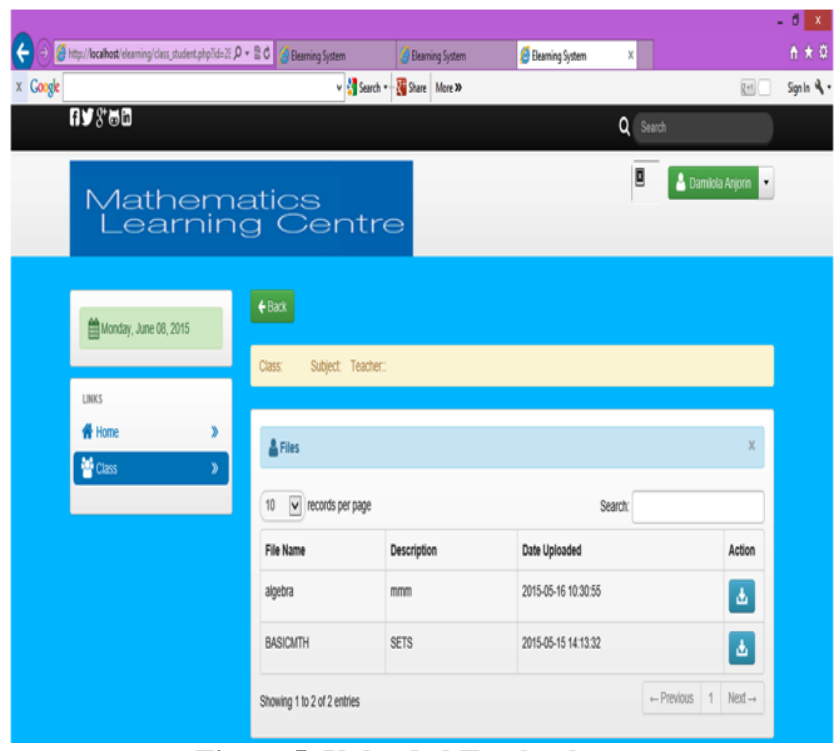

Figure 5. Uploaded Textbooks 


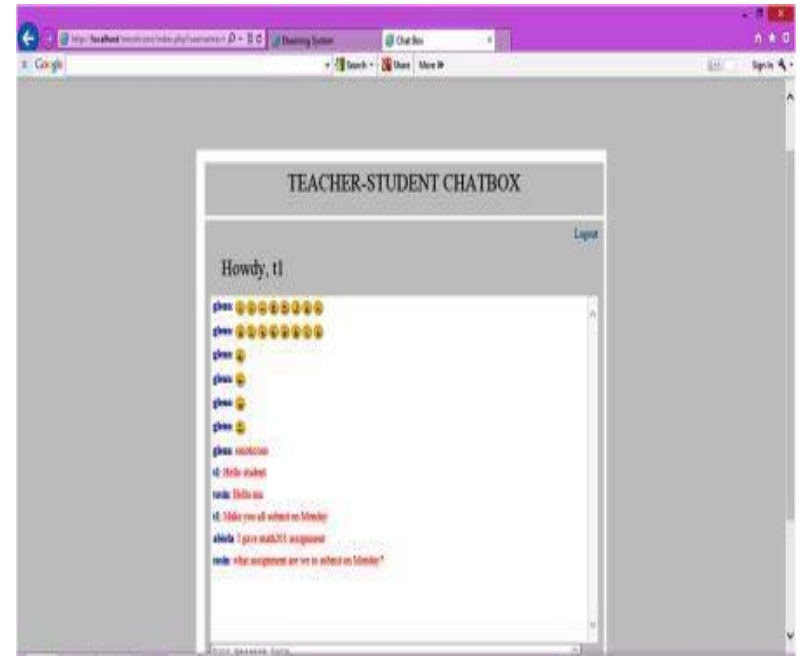

Figure 6. Teacher-to-Student Chat box Interface

\subsection{Student's Homepage Session}

Once a student has been given the password for authentication, the student enters with the password to carry out required activities. The login button verifies the student name and password input with the values in the system to determine if access will be granted. It is paramount to know that, students are limited to some areas of the system which are: downloading of files, materials, assignments and tutorials. Also, students can enter the chat room and chat with their teachers. A student is however not allowed not to see information of other student on his or her platform.

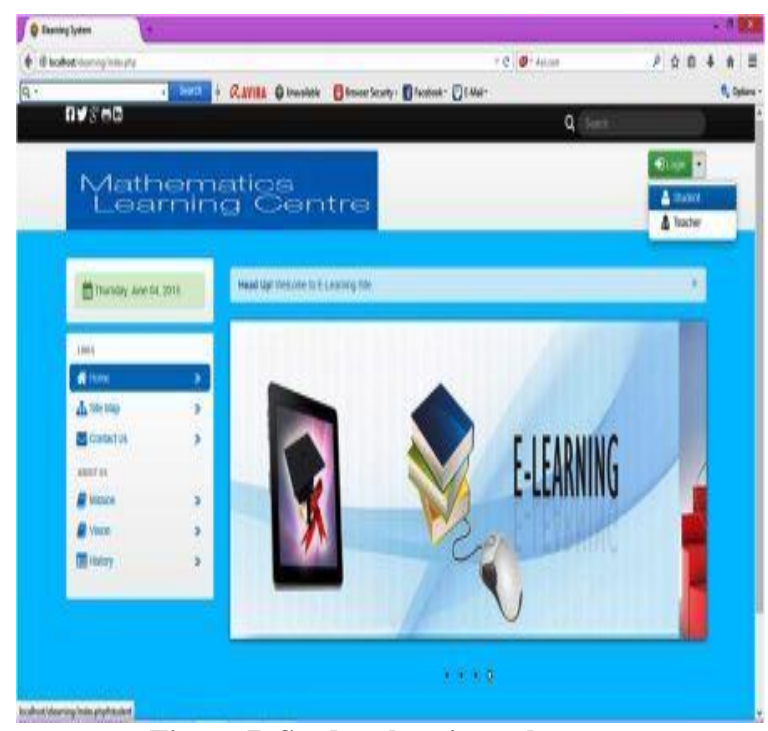

Figure 7. Student logs in to the system

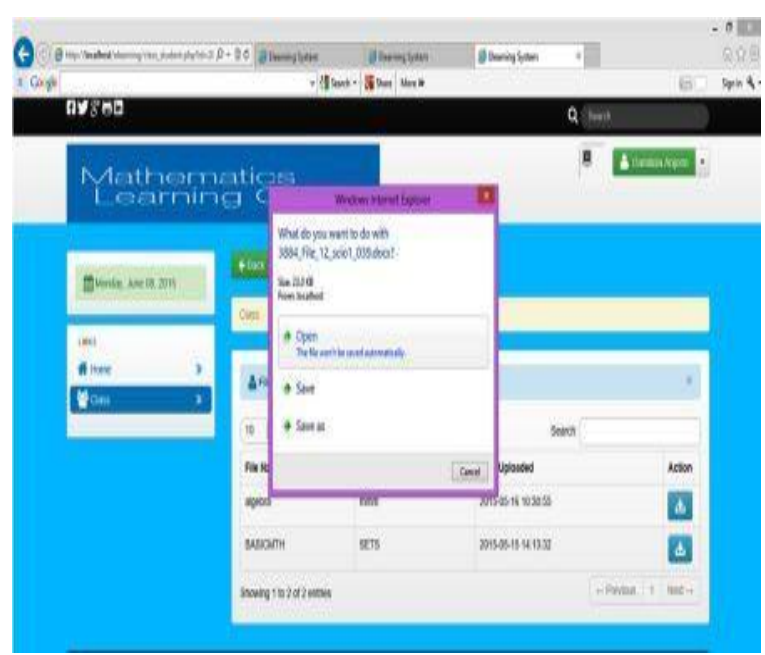

Figure 8. Student downloads textbook

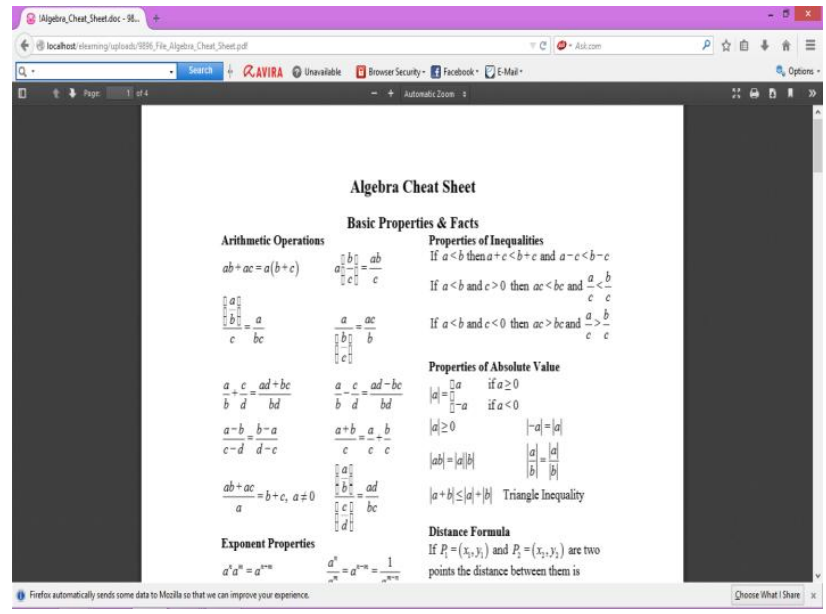

Figure 9. A downloaded tutorial with assignment

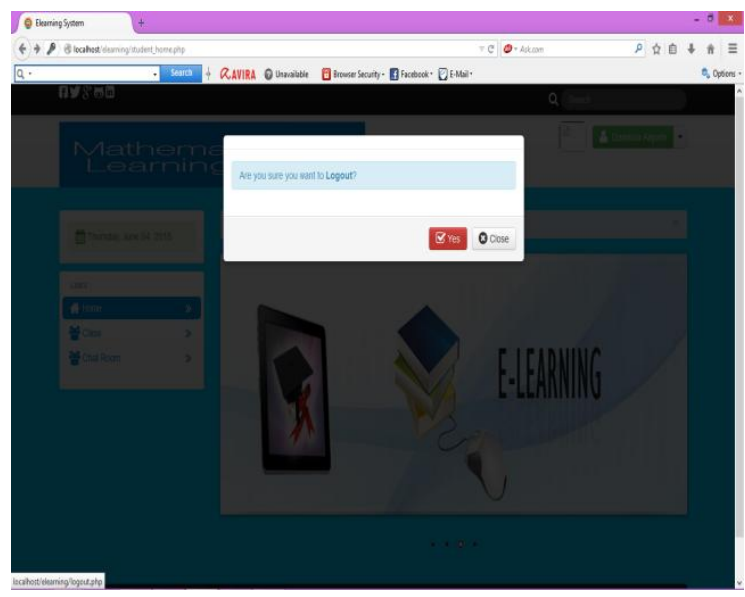

Figure 10. Log out Interface 


\section{CONCLUSION}

The system has been designed with simplicity in mind with a user friendly graphical user interface. The simplicity allows students and teachers to use the platform without any training or special set-up. This system features both knowledge building and self assessment capabilities and teachers can also monitor each student activities and students can keep learning irrespective of their locations, as it provides students with 24 hours availability of resources. Above all, with this work, students' interest in mathematics as a subject is enhanced both now and in future. E-learning system for teaching mathematics should be adopted in high schools since the applications of mathematics cannot be overemphasized in all facets of life. Also, high schools should recruit instructors with high level of ICT ability to teach the subject in order to create a friendly environment for students who taught mathematics is difficult, for them to really appreciate the beauty of the subject and its various applications

\section{ACKNOWLEDGEMENTS}

We wish to thank the anonymous reviewers for their useful suggestions in this which has gone a long way at improving the quality of this paper.

\section{REFERENCES}

[1] Sikiru A.Amoo and Akeem. B Disu (2012) "School Environmental Factors and Mathematics Teaching Effectiveness: Implication for E-learning" Library Philosophy and Practice, University of NebraskaLincoln..http://digitalcommons.un/.edu/libphi/p rac/. ISSN 1522-0222.

[2] Amoo S.A and Efunbajo A.O (2004) "A Survey of Attitudes of Primary School Teachers to the Teaching of Mathematics" Sadiku J.S (ed) Abacus Journal of the Mathematics Association of Nigeria. Vol 29(1), pp 1623.

[3] Amoo S. A and Onasanya, W. A.(2010) "Maintainig a Gender-Free Culture in Mathematics Classroom Practice in Junior Secondary Schools for the Attainment of Millenium Development Goals" Sadiku J.S (ed) Abacus Journal of the Mathematics Association of Nigeria. Vol 35 (1), pp 70-79.

[4] Ayeni O.A, Abiola O.B, Adeyemo O.A (2014) "Leveraging on E-learning Platform for the Enhancement of Computer Studies in High Schools" International Journal of Scientific and Engineering Research, Vol5, Issue 10. pp 654-658.

[5] David Wilson, Tony Callaghan, Sue Honore (2000) "Elearning the futureof learning" Elearnity Limited Version 1.0 learning directions, Masie Centre.

[6] Hussein Al-Yaseen, Mou'ath Hourani, Saheer AlJagbaub"(2012) Success and Failure of E-learning Projects: Alignment and Vision and Reality, Change and Culture" in Journal of Emerging Trends in computing and Information Sciences, Vol 3, No 2, pp277-284.

[7] Kelly.H, Ponton.M. and Rovai.A (2007) "AComparison of Student Evaluations of Teaching between Online and Face-to-Face Courses: in Journal of Internet and Higher Education, Vol. 10, pp. 89-100.

[8] Nagarajan. P and Wiselin Jiji.G (2010) "Online Educational System (e-learning)" in InternationalJournal of u-and e- Service, Science and Technology, pp 37-48.

[9] Nikhilesh Barik and Sunil Karforma (2010) "Risks and Remedies in E-learning System" in International Journal of Network Security and its Applications, Vol 4, No 1, Pp 51-59.

[10] Sangeeta Kakoty, Monohar Lal, Shikhar Sarma Kr. (2011)"E-learning as a Research Area: an Analytical Approach" in International Journal of Advanced Computer Science and Applications Vol 2, No 9, pp144148.

[11] Som Naidu (2006) "E-learning a Guidebook of principles, Procedures and Practices" in Commonwealth of Learning, commonwealth Educational Media Centre of Asia.

[12] Sebastia Xambo, Hyman Bass, Gilda Bolanos Evia, Ruedi Seiler, Mika Seppala (2006) “ E-learning mathematics" in Procedings of the International Congress of Mathematics, Madrid, spain.

[13] Tavangarian.D, M. Leypold, K. Nolting, M. Roser and D. Voigt (2004) "Is e-Learning the Solution for Individual Learning", in Electronic Journal of E-learning, Vol. 2, Issue 2, pp. 273-280. 